Aus dem Hygienischen Institut.

\title{
Ueber die Veränderung der Pathogenität und Virulenz pathogener Organismen durch künstliche Fortzüchtung in bestimmten Tierspezies und über dieVerwendung solcher Organismen zu Schutzimpfungszwecken.

\author{
Von F. Loeffler.
}

Alle lebenden Organismen sind wandelbare Wesen. Sie verändern sich unter dem Einflusse der verschiedenartigsten äußeren Faktoren, unter denen Ernährung und Temperatur die wichtigsten sind. Bei den Tieren gehen die Wandlungen außerordentlich langsam vor sich; viel schneller bei den Pflanzen. Bei diesen kann man durch Veränderung der Kulturbedingungen und durch künstliche Auslese mit großer Leichtigkeit Veränderungen erzeugen, welche sowohl die Blätter wie die Blüten, wie auch die Früchte betreffen. Das Erzeugen künstlicher neuer Spielarten wird von den Gärtnern in bedeutender Ausdehnung betrieben, und es werden auf diese Weise Spielarten gewonnen, welche weitgehende Unterschiede gegenüber der Art, von welcher man ausgegangen, darbieten. Die moderne Kultur der Rosen, der Chrysanthemen, der Tulpen, der Nelken, der Erdbeeren, der Kartoffeln etc. mit ihren staunenerregenden Erzeugnissen sind allgemein bekannt.

Sehr viel leichter noch als die phanerogamischen Pflanzen gelingt es, die kleinsten Pflänzchen, die sogenannten Bakterien, künstlich $\mathrm{zu}$ verändern.

So kann man, um nur ein Beispiel anznführen, durch Kultivieren bei höherer Temperatur, bei $37^{\circ}$, wie Schottelius gezeigt hat, den bekannten Erzeuger des Wunderblutes, den Bacillus prodigiosus umzüchten in einen Organismus, welcher keine Spur mehr des so auffallenden blutroten Farbstoffes bildet. Den Vibrio spermatozoides, der sich als kommaförmiger, lebhaft beweglicher Organismus darstellt, kann man nach Belieben in einen lange Fäden bildenden, mit noch längeren, zarten, fadenförmigen Anhängen versehenen Organismus oder aber in kurze, bewegungslose, nur mit kleinen, stummelartigen Anhängen versehene Kommaformen umbilden, je nachdem man ihn auf gewöhnlicher Nährgelatine oder anf Kohlrabigelatine längere Zeit kultiviert.

Ebenso gelingt es, manchen Organismen die für sie charakteristische Eigenschaft, Eiweibkörper zu peptonisieren, zu nehmen.

Vor allem aber kann man die krankheitserregenden organismen in ihrer Virulenz abschwächen, bzw. sie derselben vollständig berauben.

So gelingt es, wie Paste u r gelehrt hat, den Erreger des Milzbrandes durch Kultivieren bei $42-43^{\circ}$ so vollständig in seiner Virulenz abzuschwächen, daß er auch nicht einmal mehr das kleinste, für den Milzbrand hoch empfänglichste Tier, die Maus, zu töten imstande ist. Durch Kultivieren in Hühnerbonillon, wenn die Uebertragungen von Bouillon zu Bouillon in monatelangen Zwischenräumen vorgenommen wurden, gelang es ebenfalls Pasteur, den Erreger der Hühnercholera so weit in seiner Virulenz abzuschwächen, daß er bei der Impfung in den Brustmuskel eines Huhnes nur eine lokale, zur Abstoßung eines Teiles des Muskels führende Entzündung, nicht aber mehr den Tod des Huhnes herbeizuführen vermochte.

Solche Abschwächungen der Virulenz hat man mit Hilfe zahlreicher chemischer und physikalischer Agentien künstlich herbeizuführen sich angelegen sein lassen, nachdem durch die grundlegenden Untersuchungen Pasteurs die Tatsache festgestellt war, daß in ihrer Virulenz abgeschwächte Organismen mit Erfolg zu Schutzimpfungszwecken gegenüber hochvirulenter Organismen der gleichen Art verwendet werden können, 
da die Tiere, die eine nichttödliche Infektion mit den abgeschwächten Erregern überstanden hatten, sich später einer Infektion mit nichtabgeschwächten Organismen gegenüber widerstandsfähig zeigten. Bei allen diesen Untersuchungen handelte es sich ausschließlich um Veränderungen des Virulenzgrades eines bestimmten Mikroorganismus. Der zu Schutzimpfungen verwendete, künstlich abgeschwächte Organismus war identisch, artgleich mit dem virulenten Organismus, Es galt daher der Grundsatz: Immunität gegen Krankheitserreger kann erzeugt werden nur durch denselben, in seiner Virulenz veränderten Erreger, nicht aber durch Organismen, die zwar dem Erreger ähnlich sind, aber nicht zu derselben Art, sondern etwa nur zu derselben natürlichen Familie gehören. Die Erzeugung von Immunität galt daher als eine spezifische Artreaktion.

Nun lehrte aber das Studium der Pocken eine merkwürdige Abweichung von dieser Regel kennen. Die Menschenpocken und die.Kuhpocken waren als zwei voneinander verschiedene Krankheiten bekannt. Die Menschenpocken übertrugen sich mit der größten Leichtigkeit von Mensch zu Mensch, die Kuhpocken mit derselben Leichtigkeit von Rind zu Rind. Die Menschenpocken, künstlich auf das Rind übertragen, hafteten bei diesem nicht. Die Kuhpocken, auf den Menschen übertragen, erzeugten nicht die Pockenkrankheit, sondern nur eine lokale, höchstens mit leichtem Fieber verbundene Erkrankung; aber durch diese lokale Erkrankung wurden die Menschen immun, nicht nur gegen die Kuhpocken, sondern, wie Jenner bewies, auch gegen die Menschenpocken. Es lag hier somit entweder eine Ausnahme vor von dem allgemeinen Gesetz, daß nur artgleiche Organismen Immunität erzeugen können, oder aber es mußten die Erreger der Menschen- und Kuhpocken ungeachtet ihres verschiedenen pathogenen Verhaltens gegenüber Mensch und Rind doch artgleich sein, nur in ihren pathogenen Eigenschaften verändert. Die Frage war experimentell zu entscheiden. Bei den zahlreichen Uebertragungen von Menschenpockenvirus auf Rinder zeigte sich nun, daß meist allerdings die Impfungen nicht angingen, daß aber bisweilen kleine Knötchen nach denselben entstanden. Wurden diese abgekratzt und weiter auf Rinder verimpft, so entstanden wieder Knötchen, und wenn man mit der Verimpfung fortfuhr, so erzielte man schließlich schöne Pocken mit allen Charakteren der Kuhpocken. Impfte man dann diese sogenannte Variolavaccine auf den Menschen zurück, so entwickelten sich bei diesem nur lokale Pocken, wie nach der Impfung mit dem genuinen Kuhpockenvirus, und es erfolgte nicht eine allgemeine Pockeneruption, wie sie regelmäßig nach der Inokulation des Menschenpockenvirus beobachtet wird.

Aus diesen Versuchen war zu schlieben, daf das Kuhpockenvirus nichts anderes ist als das Menschenpockenvirus, welches gelegentlich einmal auf ein hochempfängliches Rind übertragen und dann im Kuhkörper fortgezüchtet seine bösartigen menschenpathogenen Eigenschaften, vor allem die Eigenschaft, im Körper des Menschen eine generalisierte Pockeneruption zu erzeugen, eingebüßt hat. Die Erreger der Menschenund der Kuhpocken müssen daher als artgleich angesehen werden. Wenn aber dem so ist, so hat die Anpassung des Menschenpockenvirus an den Körper des Rindes eine merkwürdige Veränderung des Pockenvirus herbeigeführt. Seine Pathogenität für den Menschen ist stark abgeschwächt, seine Pathogenität für das Rind aber dadurch stark erhöht worden. Besonders merkwürdig aber ist es, dal das durch die Anpassung an den Körper des Rindes veränderte Menschenpockenvirus durch andauernde Weiterzüchtung im Menschen niemals wieder seine ursprüngliche Pathogenität für den Menschen, d. h. seine Fähigkeit, einen allgemeinen Pockenausschlag, die Pockenkrankheit zu erzeugen, wieder gewinnt.

Das Beispiel der Pockenkrankheit lehrte mithin, daß durch die Anpassung eines für eine Spezies hochpathogenen Krankheitserregers an eine andere Spezies nicht sowohl eine Veränderung seiner. Virulenz, als vielmehr eine vollkommene Umwandlung seiner pathogenen Eigenschaften herbeigeführt werden kann. Diese merkwürdige Beobachtung der Veränderung der pathogenen Eigenschaften des Pockenvirus durch Fortzüchtung im Körper des Rindes stand zunächst allein da. Ohne Zutun des Menschen hatte sich die Umwandlung des
Menschenpockenvirus in das Kuhpockenvirus vollzogen und erst viele Jahre nach der Entdeckung Jenners ist die Frage der Identität oder Artgleichheit des Menschen- und Kuhpockenvirus experimentell entschieden worden. Nachdem nun aber das Experiment die Mutation des Menschenpockenvirus in das Kuhpockenvirus gegen jeden Zweifel sichergestellt hatte, mußte die Frage entstehen, ob diese Beobachtung als Wegweiser dienen konnte, um für andere pathogene Organismen künstlich die gleichen Ergebnisse zu erzielen, d. h. durch Fortzüchtung eines für eine Tierspezies pathogenen Organismus im Körper einer andern Tierspezies derartige Veränderungen in dessen pathogenen Eigenschaften herbeizuführen, daßs er zur Schutzimpfung der ersteren Tierspezies verwendet werden konnte. Die biologische Forschung hat uns bereits mehrere Tatsachen geliefert, die dartun, daß dieser Weg gangbar ist.

Ein eklatantes Beispiel bieten uns die Ergebnisse der Forschungen über die Hundswut. Ein Kaninchen, mit sogenannter Straßenwut, d. h. mit dem von einem tollwiitigen Hunde entnommenen Virus unter die harte Hirnhaut geimpft, erliegt nach etwa drei Wochen der Tollwut. Impft man nun, wie Pasteur gelehrt hat, das in den Zentralorganen vorhandene Virus von Kanin. chen zu Kaninchen weiter, so sterben die Kaninchen nach immer kürzerer Inkubationszeit, bis schließlich die geimpften Tiere nach sechs bis sieben Tagen bereits erkranken. Höher läßt sich die Virulenz für das Kaninchen nicht steigern. Dieses für das Kaninchen hochvirulent gewordene Virus hat dann aber an pathogenem Vermögen wesentliche Einbuße erlitten für den Menschen. Bei der Methode der "Immunisation forcée" werden dem zu immunisierenden Menschen ohne jeden Schaden innerhalb weniger Tage Einspritzungen gemacht von Rückenmarksemulsionen solcher an "Virus fixe" gestorbener Kaninchen, die nur wenige Tage getrocknet worden sind. Emulsionen solcher ganz frischer Rückenmarke hat man aus begreiflichen Gründen dem Menschen bisher noch nicht einzuspritzen gewagt. Wohl aber hat Marx derartige Versuche an Javaaffen und Meerkatzen angestellt. $4 \mathrm{ccm}$ Emulsion waren bei intramuskulärer Einspritzung unschädlich. Vermutlich würden solche Einspritzungen auch dem Menschen nicht schaden. Die bisher geïbte Schutzimpfungspraxis beweist aber schon zur Genüge, daß das Hundswutvirus durch seine dauernde Fortzüchtung im Kaninchengehirn für das Kaninchen in seiner Pathogenität hoch gesteigert, für den Menschen aber abgeschwächt wird. Bei der Fortzüchtung des Hundswutvirus im Affen verringert sich nach den Angaben Pasteurs die Virulenz des Hundswutvirus für diese Tierspezies, indem sich das Inkubationsstadium verlängert. Ja, es scheint schließlich bei genügend langer Fortzüchtung von Affe zu Affe eine vollkommene Aufhebung der Virulenz einzutreten. Die Versuche sind bisher in genügend langer Reihe noch nicht fortgeführt worden. Eine abschwächende Beeinflussung des Hundswutvirus durch den Affenkörper steht jedenfalls außer Zweifel. Sehr merkwürdig ist die Beobachtung Pasteurs, daß Straßenwut vom Hund auf Affen übertragen uñd von diesen nun im Kaninchen fortgezüchtet, nur eine sehr langsame Zunahme der Virulenz zeigte, derart, daß er darauf verzichtete, es zur ${ }_{\text {F }}$ raisé “ zu bringen.

Der für Hühner so hochpathogene Erreger der Hühnercholera ist für Meerschweinchen nur wenig pathogen. Es bedarf der Einspritzung relativ großer Mengen des Virus, um ein Meerschweinchen zu töten. Impft man nun aber, wie Voge s gezeigt hat, mit dem peritonealen Exsudat eines nach intraperitonealer Einspritzung von Hühnercholerabakterien verendeten Meerschweinchens ein zweites in die Bauch höhle, von diesem ein drittes und so fort, so steigert sich schließlich die Virulenz des Erregers derart, daß eine infinitesimale Menge, 1/100 Milliontel Kubikcentimeter Exsudat, welches nur einige, vielleicht nur einen Keim enthält, bereits genügt, um jedes Meerschweinchen mit Sicherheit zu töten. Zugleich mit dieser hohen Steigerung der Virulenz für das Meerschweinchen vollzieht sich nun aber keines. wegs gleichzeitig eine Steigerung der Virulenz für das Huhn, im Gegenteil, die Virulenz nimmt für diese Spezies ab, sodaß erst die tausendfache Menge der für das Meerschweinchen tödlichen Dosis imstande ist, ein Huhn tödlich zu infizieren.

Die angeführten Beispiele beweisen, daß man durch Fort. züchtung eines für eine Tierspezies pathogenen Krankheits. erregers im Körper einer anderen Spezies diesen in seiner Pathogenität für die erste Tierspezies verändern, vermindern kann. Seine Virulenz für die zweite Tierspezies wird dabei erhöht. Wir gelangen somit zu dem Begriff einer spezifischen Tierspeziespathogenität. Man kann sich diese Veränderung etwa so vorstellen, daß durch die Gewöhnung eines Erregers an eine Tierspezies das Protoplasma desselben dem Chemismus der Spezies sich anpaßt, sodaß schließlich die Körperflüssigkeiten 
dieser Tierspezies sich zu dem Erreger verhalten wie eine genaue isotonische Salzlösung. Die Körperflüssigkeiten der ersten Spezies, die von Natur aus für den Erreger isotonisch waren, sind es nun nicht mehr. Gelangt daher der für die zweite Spezies angezüchtete Erreger in die Körperflüssigkeiten der ersten Spezies zurück, so wird er nunmehr durch diese geschädigt und kann trotz seiner erhöhten Virulenz nicht mehr darin wie früher sich vermehren und verbreiten. Wenn diese Auffassung im Prinzip richtig ist, so muß es gelingen, sie auch an zahlreichen pathogenen Organismen experimentell darzutun. Es eröffnet sich somit die Aussicht, für eine Reihe von pathogenen, namentlich für die mehrere Tierspezies befallenden $0 \mathrm{r}$ ganismen tierspezies-spezifische Wandlungen ihrer Pathogenität künstlich herbeizuführen, und damit vielleicht wertvolle Hilfsmittel für die Bekämpfung jener Erreger zu gewinnen. Die Spezies-spezifische Pathogenität scheint eine hervorragende Rolle zu spielen bei der Tuberculose. Durch die Untersuchungen Kochs ist dargetan, dall die menschlichen Tuberkelbacillen spezifisch pathogen sind für den Menschen, aber nicht oder nur sehr wenig für das Rind, während die Rindertuberkelbacillen hochpathogen sind für das Rind, aber nicht oder doch nur wenig pathogen sind für den Menschen. Vermutlich handelt es sich hier um spezies-spezifische Veränderungen der Pathogenität des Tuberkelbacillus, die durch dauernde natürliche Fortzüchtung im Menschen einerseits und im Rinde anderseits im Laufe der Zeit entstanden sind. Da man mit dem menschlichen Tuberkelbacillus gegen die Rindertuberkelbacillen immunisieren kann, so müssen Menschen- und Rindertuberkelbacillen der gleichen Art angehören, wie v. Behring mit Recht betont hat. Ob die Hühnertuberkelbacillen und die Kaltblütertuberkelbacillen ebenfalls derselben Art angehören und als tierspezifisch in ihrer Pathogenität verändert anzusehen sind, oder ob sie andern, aber $\mathrm{zu}$ derselben natürlichen Pflanzenfamilie gehörenden Arten angehören, ist zurzei nicht $\mathrm{zu}$ entscheiden, da die mit diesen Organismen angestellten Immunisierungsversuche ein unzweideutiges Resultat noch nicht ergeben haben.

Die Veränderungen im pathogenen Verhalten und in der Virulenz, welche durch die Anpassung eines pathogenen Organismus an bestimmte Tierspezies hervorgerufen werden, brauchen nicht etwa nur dahin zu gehen, dab die Pathogenität des betreffenden Erregers für die Tierspezies, an welche er angepaßt ist, erhöht, für alle andern Tierspezies, auf die er übertragbar ist, aber verringert wird. Es ist sehr wohl denkbar, dal durch die Erhöhung der Pathogenität für eine Tierspezies zugleich auch eine Steigerung derselben für andere Tierspezies bewirkt wird. Dies dürfte z. B. der Fall sein bei dem Rindertuberkelbacillus, der eine hohe Pathogenität für alle für den Tuberkelbacillus empfänglichen Tierspezies aufweist. Es ist auch denkbar, dal die an eine Tierspezies angepaiten Organismen, abgesehen von ihrer spezifischen Tierspeziespathogenität noch verschiedene Grade von Virulenz darbieten. So gibt es hochvirulente und schwachvirulente Menschentuberkelbacillen, und hochvirulente und schwachvirulente Rindertuberkelbacillen. Durch die Anpassung an eine neue Tierspezies muß die Pathogenität eines Organismus für die Tierspezies, für die er ursprünglich angepaßt war, durchaus nicht etwa vollkommen verschwinden. Bei dieser Auffassung kann es daher garnicht wunderbar erscheinen, daß gelegentlich einmal ein in den Menschenkörper eingeführter Rindertuberkelbacillus gewisse krankhafte Veränderungen in diesem hervorruft, aber diese Veränderungen werden anderer, geringfügigerer Art sein als die durch einen an den Menschen angepaßten Tuberkelbacillus hervorgerufenen. Es ist weiterhin noch der Fall denkbar, daß durch die Uebertragung und Fortzüchtung in einer neuen Tierspezies die Pathogenität und die Virulenz der Erreger für diese Spezies, wie auch für die Ursprungsspezies, mithin für beide Spezies entweder erhöht oder aber herabgesetzt wird. Kurz, es bieten sich eine Menge von Möglichkeiten dar auf dem Gebiete der Tierspeziespathogenität, die man in keinem Falle voraussehen oder vorausbestimmen kann. Das experimentelle Studium muß erst nach dieser Richtung hin Aufklärung bringen.

Wenn man nun die Idee verfolgt, eine für die Schutz- impfung einer Tierspezies geeignete Tierspeziesmodifikation eines Erregers zu finden, so ist man ganz auf das Experiment angewiesen. Man wird die verschiedenen Tierspezies durchprobieren müssen und die etwaigen durch Fortzüchten in den verschiedenen Tierspezies erzielten Veränderungen durch den Versuch ermitteln. Im allgemeinen wird man für die Fortzüchtung am besten solche Tierspezies wählen, die im System entfernt stehen von der empfänglichen Spezies und für den Erreger zwar empfänglich, aber weniger empfänglich sind wie die Spezies, in welcher der Erreger spontan sich fortzuzüchten pflegt. Meist vollzieht sich die natürliche Fortzüchtung eines pathogenen Organismus nur in ein er bestimmten Tierspezies und nur gelegentlich gelangt er in Individuen anderer Spezies, in denen aus den verschiedensten Gründen eine längere Fortzüchtung aber nicht erfolgt. Solche Spezies sind eventuell zu versuchen. Schweine sind zum Beispiel im allgemeinen wenig empfänglich gegen die Einimpfung des Milzbrandvirus, aber bisweilen kommen spontane Milzbranderkrankungen beiSchweinen zur Beobachtung. Diese spontan auf das Schwein übertragenen Erreger wären nun z. B. künstlich im Schweinekörper fortzuzüchten und es wäre zu prüfen, ob sie durch diese Fortzüchtung in ihrem pathogenen Verhalten für Schafe und Rinder verändert würden. Ich möchte darauf hinweisen, dal der Modus der Infektion, ob diese per os, subcutan, intramuskulär, intravenös, in das Parenchym bestimmter Organe geschieht, bei derartigen Versuchen eine wesentliche Rolle zu spielen scheint, wie namentlich die Untersuchungen über das Hundswutvirus ergeben haben.

Wie lange Zeit verstreichen muf, wie lange der Organismus in der neuen Tierspezies fortgezüchtet werden muß, bis eine Aenderung seiner Pathogenität eintritt, wird sich a priori nicht sagen lassen. Wie das Beispiel des Pockenvirus lehrt, kann sich die Wandlung der Pathogenität innerhalb weniger Generationen vollziehen, sie kann aber auch eventuell erst nach einer größeren Reihe von Uebertragungen sich einstellen, wie es bei dem Hundswutvirus der Fall ist. Jedenfalls darf man nicht zu schnell die Hoffnung, eine zur Schutzimpfung geeignete Modifikation zu erzielen, aufgeben.

Von den vorstehenden Erwägungen geleitet, habe ich seit mehreren Jahren versucht, den Erreger einer für die Landwirtschaft hoch bedeutungsvollen Seuche, den Erreger der Maulund Klauenseuche, die in erster Linie die Rinder befällt, dann aber auch auf Schweine und Schafe übertragbar ist, für eine der weniger empfänglichen Tierspezies, für das Schwein, spezifisch pathogen zu machen, um dann zu prüfen, ob der für diese Tierspezies angezüchtete Erreger für das Rind an Pathogenität verlieren würde, und ob eventuell, wenn eine solche Aenderung zu konstatieren war, die für die Rinder in ihrer Pathogenität veränderte Modifikation zur Schutzimpfung der am stärksten von der Seuche bedrohten Rinder zu verwenden sein würde.

Schweine, die mit frisch von Rindern gewonnener Lymphe infiziert wurden, erkrankten prompt. Impfte man nun von Schwein zu Schwein weiter, so boten schon nach wenigen Uebertragungen die mit gleichen Mengen Lymphe geimpften Tiere immer schwächere Krankheitserscheinungen dar, und nach vier bis fünf Uebertragungen blieben die geimpften Tiere vollständig gesund. Es gelang also nicht, das Virus im Körper des erwachsenen Schweines fortzuzüchten, wohl aber gelang dies in etwa sechs Wochen alten Ferkeln. Es zeigte sich nun bei der Fortzüchtung der Lymphe im Ferkel, daß die Virulenz des Virus für diese Tierspezies sich durch Hunderte von Generationen erhalten ließ. Die Tiere erkrankten ebenso wie wenn sie mit frischer Rinderlymphe geimpft wurden. Nur ergab es, daß die Giftigkeit der Lymphe mit der Zeit abnahm und eine Dosis von 1/10 ccm Lymphe, die von frisch erkrankten Rindern gew onnen, die Ferkel stets tötete, den Tod der Tiere nicht mehr herbeiführte. Nachdem nun die Lymphe durch eine lange Reihe von Ferkeln hindurchgezüchtet war, zeigte es sich bei Infektionsversuchen von Rindern mit dieser Lymphe, daß die Virulenz der Lymphe für das Rind ohne Zwweifel abgenommen hatte. Während eine frische virulente Lymphe in der Dosis von $1 / 40000$ bis $1 / 20000 \mathrm{ccm}$ Rinder prompt krank machte, konnte von der durch Ferkelpassagen gewonnenen Lymphe Rindern $1 / 300$, bisweilen sogar $1 / 100 \mathrm{ccm}$ eingespritzt werden, ohne daß sie erkrankten. Es zeigte sich dann weiter, daß diese eine Injektion genügte, um den Rindern einen gewissen Grad von Immunität zu verleihen. Indessen 
waren die Ergebnisse durchaus nicht konstante. Rückschläge in der Virulenz der Lymphe kamen häufig vor. Ich machte nun die interessante Beobachtung, daß die Rasse der zur Fortzüchtung der Lymphe benutzten Ferkel hierfür von besonderer Bedeutung war. Wenn, wie es häufig vorkommt, Ferkel anderer Rassen zur Fortzüchtung verwendet werden mußten, so trat entweder eine schnelle Abnahme, ja ein vollkommenes Verschwinden der Virulenz ein, oder aber eine akute Steigerung derselben für das Ferkel sowohl wie für das Rind. Erst als durch Vermittlung eines großen Züchters dauernd Ferkel derselben Rasse für die Fortzüchtung verwendet werden konnten, wurde das Ergebnis ein gleichmäßjigeres. Die Ferkel erkrankten nach Einspritzung von 1/10 $\mathrm{ccm}$ Lymphe prompt nach zwei Tagen in typischer Weise. Die Prüfung dieser Lymphe an Rindern ließ eine unzweifelhafte Abnahme der Virulenz für das Rind erkennen. Die Rinder erkrankten nicht mehr nach $1 / 100 \mathrm{ccm}$ Lymphe, ja es kam vor, daß sie auch nach $1 / 25$ und selbst $1 / 10 \mathrm{ccm}$ frischer Lymphe nicht mehr krank wurden.

Es zeigte sich nun weiter, dal die Rinder, die nach der Einspritzung der Lymphe nicht erkrankt waren, sich einer relativ hohen Immunität erfreuten, die mehrere Monate andauerte. Gleichwohl erschien eine praktische Verwendung dieser durch Fortzüchtung in Ferkeln derselben Rasse für das Rind abgeschwächten Lymphe für die Immunisierung von Rindern in der Praxis nicht ratsam, weil die individuelle Empfänglichkeit der verschiedenen Rinder für die Infektion als ein störender Faktor sich zeigt. Trotz der großen Billigkeit der Methode konnte dieselbe für die Praxis doch noch nicht empfohlen werden, weil die Gefahr bestand, daß einzelne hochempfängliche Tiere nach der Einspritzung einer Dosis Lymphe, die von den meisten Tieren anstandslos vertragen wurde, doch noch erkrankten. Bei einer Schutzimpfung der Rinder gegen die Maul- und Klauenseuche ist eine Methode erforderlich, bei welcher jede auch noch so leichte Erkrankung einzelner Tiere ausgeschlossen ist. Während z. B. für die Schutzimpfung der Rinder gegen die Rinderpest eine Methode, bei welcher die schutzgeimpften Tiere leicht erkranken, von allergrößtem Wert ist, weil durch die leichte Erkrankung die natürliche Infektion, die fast immer zum Tode führt, verhütet wird, bedarf es für die Schutzimpfung gegen die Maul- und Klauenseuche einer Methode, die jede Erkrankung vermeidet, weil die Tiere an der Maul- und Klauenseuche bei uns wenigstens nicht sterben und weil allein die Erkrankungen der Tiere die groben wirtschaftlichen Schädigungen bedingen. Ich suchte deshalb die Gefahr einer Infektion einzelner Tiere durch die abgeschwächte Lymphe dadurch zu beseitigen, daß ich den schutzzuimpfenden Rindern eine kleine Menge hochwirksamen, durch Vorbehandlung von Rindern mit steigenden Mengen hochvirulenter Lymphe gewonnenen Schutzserums, gleichzeitig, aber getrennt von der Ferkellymphe einspritzte. Eine Reihe von Versuchen ergab, daß $10 \mathrm{ccm}$ Serum, auf der einen Seite des Halses subcutan eingespritzt, genügten, um $4 / 100$ bis $5 / 100$ ccm Ferkellymphe, die auf der andern Halsseite subcutan eingespritzt wurde, vollkommen ungefährlich zu machen. Die Dosis von $4 / 100$ bis $5 / 100$ ccm Ferkellymphe wurde gewählt, weil sich ergeben hatte, daß diese nötig war, um eine gute Grundimmunität zu erzielen, Die so behandelten Rinder vertrugen drei bis vier Wochen nach dieser ersten Einspritzung 4/100 ccm Lymphe subcutan, ohne zu erkranken. Sie konnten dann zusammen mit kranken Tieren in einem verseuchten Stalle gehalten werden und blieben gesund. Bei entsprechenden Versuchen, die früher mit virulenter, aus frischen Seuchenausbrüchen gewonnener Lymphe angestellt worden waren, hatte sich herausgestellt, dal eine Erkrankung der Rinder nicht hatte verhütet werden können, wenn denselben $1 / 100 \mathrm{ccm}$ Lymphe und große Dosen von Serum getrennt eingespritzt worden waren. Erst durch die dauernde Fortzüchtung im Ferkel war eine solche Abschwächung erzielt worden, daß $10 \mathrm{ccm}$. Serum genügten, um bei getrennter Einspritzung $4 / 100$ bis $5 / 100 \mathrm{ccm}$ Lymphe unschädlich $\mathrm{zu}$ machen.

Nach den bisherigen Versuchen dürfte sich die neue, vollkommen ungefährliche Methode auch für Schutzimpfungen in der Praxis sehr wohl eignen. Die Fortzüchtung der Lymphe im Ferkelkörper wird noch dauernd weiter geführt werden. Es wird sich ergeben, ob allmählich noch eine weitere Abnahme der Pathogenität der Lymphe für das Rind sich einstellen wird derart, daß diese Lymphe ohne gleichzeitige Einspritzung von Schutzserum in den zur Herbeiführung einer genügenden Im- munität ausreichenden Dosen Rindern ohne jede Gefahr eingespritzt werden kann. Eine einfache Einspritzung von abgeschwächter Lymphe würde als das Ideal einer Schutzimpfung gegen diese so außerordentlich leicht übertragbare, in ihrer Ansteckungsfähigkeit den Pocken sehr wohl vergleichbare Krankheit anzusehen sein.

Jedenfalls hat sich die von mir verfolgte Idee, durch Anpassung des Maul- und Klauenseuchenvirus an den Ferkelkörper ein zur Schutzimpfung verwendbares, abgeschwächtes Virus zu gewinnen, als fruchtbringend erwiesen. Die Hoffnung, auch gegenüber andern pathogenen Organismen auf analoge Weise ein zur Schutzimpfung geeignetes Material gewinnen zu können, ist dadurch neu belebt worden. 